\title{
Pengaruh Citra Perusahaan dan Kepuasanpelanggan terhadap Loyalitas Pelanggan pada Toko Bunga Pertiwi Cabang Sulanyah
}

\author{
I Gusti Bagus Kelvin Wira Yudha ${ }^{1 *}$, Ni Nyoman Yulianthini ${ }^{2}$
}

1,2Universitas Pendidikan Ganesha, Singaraja - Indonesia

\author{
A R T I C L E IN F O \\ Article history: \\ Received February, 26 \\ 2021 \\ Received in revised form \\ November, 282021 \\ Accepted November, 28 \\ 2021 \\ Available online December, \\ 252021 \\ Kata Kunci: \\ Citra perusahaan, kepuasan \\ pelanggan, loyalitas \\ pelanggan \\ Keywords: \\ Company image, customer \\ satisfaction, customer \\ loyalty
}

\begin{abstract}
A B S T R A K
Penelitian ini bertujuan untuk memperoleh temuan yang teruji tentang pengaruh citra perusahaan terhadap loyalitas pelanggan, pengaruh kepuasan pelanggan terhadap loyalitas pelanggan, dan pengaruh citra perusahaan dan kepuasan pelanggan terhadap loyalitas pelanggan. Desain penelitian yang digunakan adalah penelitian kuantitatif kausal. Subjek dalam penelitian ini adalah konsumen yang sudah menjadi pelanggan Toko Bunga Pertiwi Cabang Sulanyah dan objek dalam penelitian ini adalah citra perusahaan, kepuasan pelanggan, dan loyalitas pelanggan. Data dikumpulkan dengan pencatatan dokumen dan metode kuesioner, serta dianalisis dengan analisis regresi linier berganda. Hasil penelitian menunjukkan bahwa 1) citra perusahaan berpengaruh positif dan signifikan terhadap loyalitas pelanggan Toko Bunga Pertiwi, 2) kepuasan pelanggan berpengaruh positif dan signifikan terhadap loyalitas pelanggan Toko Bunga Pertiwi, 3) citra perusahaan dan kepuasan pelanggan berpengaruh siginifikan terhadap loyalitas pelanggan Toko Bunga Pertiwi.
\end{abstract}

\section{A B S T R A C T}

This study aims to obtain tested findings about the effect of corporate image on customer loyalty, the effect of customer satisfaction on customer loyalty, and the effect of corporate image and customer satisfaction on customer loyalty. The research design used was causal quantitative research. The subjects in this study are consumers who have become customers of the Sulanyah branch of the Pertiwi Flower Shop and the objects in this study are company image, customer satisfaction, and customer loyalty. Data were collected by document recording and questionnaire method, and analyzed by multiple linear regression analysis. The results showed that 1) company image had a positive and significant effect on customer loyalty of Toko Bunga Pertiwi, 2) customer satisfaction had a positive and significant effect on customer loyalty of Toko Bunga Pertiwi, 3) company image and customer satisfaction had a significant effect on customer loyalty of Toko Bunga Pertiwi.

Copyright () Ekuitas: Jurnal Pendidikan Ekonomi. All rights reserved.

\footnotetext{
${ }^{1}$ Corresponding author.

E-mail : rohmatalimuntaha@gmail.com (I Gusti Bagus Kelvin Wira Yudha)
} 


\section{Pendahuluan}

Persaingan di era 4.0 ini semakin ketat disegala bidang, tidak terkecuali persaingan bisnis. Berbagai bisnis di Indonesia semakin berkembang, salah satu bisnis yang menjanjikan adalah bisnis kuliner. Khususnya di Bali, roti dan kue tradisional sering kali digunakan untuk melengkapi sajen pada upacaraupacara keagamaan. Melihat peluang bisnis yang besar ini tentunya banyak pebisnis yang berminat membangun toko roti dan kue. Hal ini menimbulkan banyaknya toko roti dan kue disuatu daerah yang mengakibatkan persaingan semakin ketat. Hal ini juga dialami oleh Toko Bunga Pertiwi Cabang Sulanyah, Kecamatan Seririt yang merupakan salah satu toko roti dan kue yang terkenal di wilayah Sulanyah Seririt dan Singaraja. semakin bertumbuhnya bisnis Roti dan Kue di wilayah Seririt yang ditunjukkan dengan mulai banyaknya toko-toko roti dan kue yang sejenis sehingga mau tidak mau akan mempengaruhi jumlah penjualan toko. Data jumlah penjualan Toko Bunga Pertiwi dari tahun 2015 - 2019 seperti pada Tabel 1.

Tabel 1. Jumlah Penjualan Toko Bunga Pertiwi dari Tahun 2015 - 2019

\begin{tabular}{ccl}
\hline No & Tahun & Jumlah Penjualan (Rp) \\
\hline 1 & 2015 & 1.560 .457 .000 \\
2 & 2016 & 1.590 .678 .000 \\
3 & 2017 & 1.807 .863 .000 \\
4 & 2018 & 1.799 .546 .000 \\
5 & 2019 & 1.798 .659 .000 \\
\hline
\end{tabular}

Sumber: Data diolah, 2020

Berdasarkan Tabel 1. di atas, tampak bahwa jumlah penjualan tiap tahun berfluktuasi, dan 3 tahun terakhir mengalami penurunan. Banyak faktor yang mempengaruhi mengapa jumlah penjualan bisa berfluktuasi, salah satunya adalah karena banyaknya pesaing. Guna menghadapi para pesaing, banyak pebisnis mencari cara agar tetap survive. Salah satunya adalah dengan menumbuhkan loyalitas kepada pelanggannya. (Rahayu et al., 2016) menyatakan bahwa membuat pelanggan menjadi setia atau loyal terhadap perusahaan adalah jantung dari setiap bisnis. Hal ini dikarenakan dengan membuat pelanggan menjadi setia atau loyal terhadap perusahaan adalah jantung dari setiap bisnis. Hal ini dikarenakan dengan membuat pelanggan menjadi setia atau loyal terhadap perusahaan, tentunya akan terjadi pembelian berulang dan penyebaran informasi positif oleh konsumen yang setia atau loyal tentang perusahaan melalui word of mouth kepada calon pelanggan perusahaan sehingga akan membantu perusahaan dalam mencapai tujuannya.

Terdapat beberapa faktor yang dapat mempengaruhi loyalitas pelanggan untuk dapat mempertahankan atau pun mencari pelanggan yang loyal tentunya. Salah satunya adalah citra perusahaan atau toko. Citra perusahaan merupakan salah satu bagian terpenting yang dimiliki oleh suatu perusahaan baik perusahaan besar maupun perusahaan kecil. Menurut (Nguyen \& Leblanc, 2016), citra perusahaan merupakan hasil dari kumpulan proses di mana pelanggan membandingkan berbagai atribut yang dimiliki oleh perusahaan. Atribut yang dimaksud misalnya produk, harga, kualitas produk dan kualitas layanan. Pelanggan akan membuat persepsi yang subyektif mengenai perusahaan dan segala aktivitasnya.

(Rahayu et al., 2016) menyatakan bahwa citra toko berpengaruh terhadap loyalitas pelanggan. Hal ini sama dengan yang ditemukan oleh (Kurniawati et al., 2014) yang menyatakan bahwa reputasi perusahaan berpengaruh terhadap loyalitas pelanggan. Hal ini juga didukung oleh penelitian oleh (Rahayu et al., 2016) yang memperoleh hasil bahwa citra toko dan nilai yang dipersepsikan memiliki pengaruh signifikan terhadap loyalitas pelanggan. Penelitian (Suratno et al., 2016), juga memperoleh hasil yang menyatakan bahwa citra perusahaan berpengaruh positif signifikan terhadap loyalitas pelanggan. Akan tetapi, (Lai \& et al., 2009) menemukan bahwa loyalitas pelanggan tidak dipengaruhi oleh citra perusahaan. Penelitian yang dilakukan (Kurniawati et al., 2014) memperoleh hasil bahwa citra merek tidak berpengaruh signifikan terhadap loyalitas pelanggan.

Pasar yang didalamnya terdapat tingkat persaingannya cukup tinggi, mendorong perusahaan mulai bersaing untuk memberikan kepuasan kepada pelanggannya agar pelanggan mempunyai kesetiaan yang tinggi terhadap kue, dan roti yang ditawarkan pengusaha. Apabila pelanggan merasa tidak puas maka pelanggan tersebut tidak akan kembali lagi pada perusahaan tersebut. Loyalitas (loyalty) sebagai komitmen yang di pegang secara mendalam untuk membeli atau mendukung kembali produk atau jasa 
yang disukai di masa depan meski pengaruh situasi dan usaha pemasaran berpotensi menyebabkan pelanggan beralih. Ketika pelanggan menerima kualitas pelayanan yang lebih baik dari uang yang dikeluarkannya, mereka percaya menerima nilai yang baik (good value), di mana hal ini akan meningkatkan loyalitasnya kepada penyedia jasa. Pelanggan juga seringkali dapat menarik kesimpulan mengenai kualitas suatu jasa (service) atau pelayanan berdasarkan penilaian mereka terhadap tempat atau lokasi, orang, peralatan, alat komunikasi dan citra perusahaan yang mereka lihat sebelum mereka memutuskan untuk melakukan pembelian kembali dimasa mendatang (Rahayu et al., 2016).

Hasil penelitian (Suratno et al., 2016) juga memperoleh hasil bahwa kepuasan pelanggan berpengaruh positif signifikan terhadap loyalitas pelanggan. Hasil penelitian (Jean, 2018) memperoleh hasil berbeda dengan penelitian sebelumnya yang meperoleh hasil bahwa kepuasan pelanggan tidak berpengaruh signifikan terhadap loyalitas pelanggan. Hal ini juga didukung oleh penelitian (Rain \& Dkk., 2018) yang memperoleh hasil kepuasan pelanggan tidak berpengaruh signifikan terhadap loyalitas pelanggan karena banyak faktor pelanggan menjadi loyal terhadap toko atau perusahaan tertentu.

Dalam penelitian ini, yang membedakan dengan penelitian sebelumnya adalah penekanan penggunaan variabel citra perusahaan atau toko dan kepuasan pelanggan terhadap loyalitas pelanggan yang dilakukan di Toko Bunga Pertiwi Cabang Sulanyah, Seririt. Berdasarkan uraian latar belakang sebelumnya, penting dilakukan penelitian dengan judul "Pengaruh Citra Perusahaan dan Kepuasan Pelanggan terhadap Loyalitas Pelanggan pada Toko Bunga Pertiwi Cabang Sulanyah"

Berdasarkan latar belakang penelitian dan rumusan masalah yang ada, maka tujuan penelitian ini adalah adalah untuk menganalisis dan menguji tentang hal-hal sebagai berikut. (1) Pengaruh citra perusahaan terhadap loyalitas pelanggan Toko Bunga Pertiwi, Cabang Sulanyah, Kecamatan Seririt. (2) Pengaruh kepuasan pelanggan terhadap loyalitas pelanggan Toko Bunga Pertiwi, Cabang Sulanyah, Kecamatan Seririt. (3) Pengaruh citra perusahaan dan kepuasan pelanggan terhadap loyalitas pelanggan Toko Bunga Pertiwi, Cabang Sulanyah, Kecamatan Seririt.

Hasil penelitian ini diharapkan dapat memberikan manfaat sebagai berikut. (1) Manfaat Teoritis, hasil dari penelitian ini diharapkan dapat menambah dan memperdalam ilmu pengetahuan dalam bidang manajemen khususnya manajemen pemasaran tentang pengaruh citra perusahaan dan kepuasan pelanggan terhadap loyalitas pelanggan.(2) Manfaat Praktis, hasil penelitian ini diharapkan dapat memberikan gambaran serta informasi kepada perusahaan maupun toko terkait masalah citra perusahaan dan kepuasan pelanggan terhadap loyalitas pelanggan.

Secara teoritik penelitian ini dilandasi beberapa teori tentang loyalitas yang merupakan sebuah keputusan konsumen secara sukarela untuk terus menerus berlangganan pada sebuah perusahaan tertentu dalam periode waktu yang panjang. Dalam konteks bisnis loyalitas dapat digunakan untuk menjelaskan kesediaan konsuman untuk berlangganan secara terus-menerus pada sebuah perusahaan dalam jangka waktu yang lama, pembelian dan menggunakan produk atau jasa berulang dan secara sukarela merekomendasikan kepada orang lain (Suratno et al., 2016). Menurut (Supriyanto \& Ernawati, 2010) menyebutkan bahwa dalam perkembangannya loyalitas memiliki dimensi-dimensi dan indicator sebagai berikut: (1) Affective loyalty, kemauan konsumen untuk menggunakan suatu produk/jasa yang sama secara kontinu dalam waktu panjang. (2) Action loyalty, membeli atau menggunakan jasa yang sama secara berulang- ulang (faktual). (3) Advocator loyalty, secara sukarela dan eksklusif (kesadaran sendiri) merekomendasikan produk/jasa kepada teman, relasi dan kelompok masyarakat lainya (sikap dan faktual). (4) Conative loyalty, membuat komitmen untuk menggunakan lagi bila membutuhkan.

$(\mathrm{Wu}, 2011)$ menyatakan bahwa citra toko merupakan jalan pemikiran pembeli yang menggambarkan toko, sebagian melihat fungsi kualitas dan sebagian lagi melihat suasana toko sebagai atribut psikologis. Citra perusahaan dapat menjadi informasi isyarat ekstrinsik bagi pembeli potensial di mana mungkin atau tidak mempengaruhi loyalitas pelanggan, misalnya kesediaan untuk memberikan word of mouth yang positif (Rahayu et al., 2016). Dimensi dari citra perusahaan ke dalam tiga dimensi dan indikator berikut. (1) Recognition merupakan kemampuan konsumen untuk mengenali dan mengingat suatu merek di dalam benak pikiran dan seberapa kuat nama perusahaan dikenal oleh konsumen. Konsumen akan mudah mengingat suatu merek ketika melihat atau menjumpai gambar atau ciri-ciri tertentu. (2) Reputation merupakan kekuatan merek yang dapat membangun status dibenak konsumen, sehingga reputation ini sejajar dengan persepsi kualitas. (3) Brand Loyalty merupakan seberapa besar kesetiaan pelanggan terhadap produk.

Loyalitas pelanggan erat hubungannya dengan kepuasan konsumen, semakin terpuaskan konsumen terhadap keinginannya, akan membuat konsumen kembali lagi untuk membeli produk tersebut dan konsumen yang loyal terhadap produk itu. Terciptanya kepuasan pelanggan dapat memberikan manfaat, diantaranya: hubungan antara perusahaan dan pelanggan menjadi harmonis, memberikan dasar yang baik bagi pembelian ulang dan terciptanya loyalitas pelanggan, dan membentuk suatu rekomendasi dari mulut ke mulut (word of mouth) yang menguntungkan bagi perusahaan (Kurniawati et al., 2014). 
Terdapat lima indikator kepuasan pelanggan diantaranya: (1) Harga (Price), harga murah adalah sumber kepuasan yang penting karena akan mendapatkan value for money yang tinggi. (2) Kualitas layanan (service quality), menyangkut tiga hal yaitu sistem, teknologi dan manusia. Kepuasan pelanggan terhadap kualitas pelayanan biasanya sulit ditiru karena pembentukan attitude dan behaviour yang seiring dengan keinginan perusahaan bukanlah pekerjaan mudah. Pembenahan harus dilakukan mulai dari proses rekruitmen, training dan budaya kerja. (3) Kualitas produk (product quality), menyangkut pelanggan merasa puas setelah membeli dan menggunakan produk tersebut apabila kualitas produk yang baik. (4) Faktor emosional (emotional factor), menyangkut konsumen atas kepuasan yang diperoleh dalam menggunakan suatu produk/jasa yang menimbulkan rasa bangga dan rasa percaya diri. (5) Kemudahan (Efficiency), menyangkut kemudahan dalam memeroleh produk atau jasa tersebut dan kemudahan dalam pembayaran dapat membuat pelanggan akan semakin puas bila relatif mudah, nyaman dan efisien dalam mendapatkan suatu produk atau pelayanan.

\section{Metode}

Penelitian ini menggunakan rancangan penelitian kuantitatif kausal. Desain penelitian ini bertujuan menentukan hubungan dan pengaruh dari suatu variabel terhadap variabel lainnya, yaitu menganaslisis hubungan sebab akibat antar variabel independen (X) dan variabel dependen (Y). Desain kuantitatif kausal dapat dilakukan dengan langkah-langkah sebagai berikut (a) merumuskan masalah, (b) landasan teori, (c) merumuskan hipotesis, (d) mengumpulkan data, (e) analisis data, dan (f) menyusun laporan dan menyimpulkan. Adapun variabel bebas dalam penelitian ini adalah citra perusahaan (X1) dan kepuasan pelanggan (X2), sedangkan variabel terikat adalah keputusan pembelian (Y).

Subjek dari penelitian ini adalah konsumen Toko Bunga Pertiwi Cabang Sulanyah, dan objek dalam penelitian ini adalah citra perusahaan, kepuasan pelanggan dan loyalitas pelanggan. Banyaknya sampel dalam penelitian tergantung dari jumlah parameter yang diestimasi. Pedomannya adalah 5-10 kali jumlah parameter yang diestimasi jumlah sampel adalah 5-10 dikali jumlah indikator (Ferdinand, 2006). Populasi dalam penelitian ini adalah konsumen Toko Bunga Pertiwi Cabang Sulanyah, Kecamatan Seririt. Dari populasi tersebut, penelitian ini akan menggunakan konsumen yang sudah loyal berbelanja di Toko Bunga Pertiwi Cabang Sulanyah, Kecamatan Seririt untuk dijadikan sampel. Penelitian ini menggunakan 12 indikator. Sehingga minimal sampel yang bisa diambil dalam penelitian ini adalah 12 x $5=60$ dan sampel maksimal yang bisa diambil dalam penelitian ini adalah $12 \times 10=120$. Pada penelitian ini menggunakan sampel sebanyak 100 responden. Teknik pengumpulan sampel yang digunakan dalam penelitian ini adalah dengan menggunakan teknik sampling proporsional. Menurut (Sugiyono, 2011) , teknik sampling proporsional yaitu suatu sampel yang dihitung berdasarkan perbandingan. Teknik ini digunakan, apabila populasi atau unsur yang tidak homogen dan berstrata secara proporsional.

Teknik penentuan sampel yang dipakai dalam penelitian ini adalah purposive sampling. Purposive sampling adalah teknik pengambilan sampling di mana sampel dipilih berdasarkan penilaian peneliti bahwa yang dipilih adalah pihak yang tepat untuk dijadikan sampel penelitiannya. Sampel yang diambil dalam penelitian ini memiliki kriteria-kriteria yaitu : (1) konsumen yang sudah loyal berbelanja di Toko Bunga Pertiwi Cabang Sulanyah,Kecamatan Seririt; konsumen yang pernah berbelanja minimal 3 kali dalam 1 bulan; (2) konsumen yang sudah berusia 17-50 tahun yang dianggap mampu dan paham dalam mengisi kuesioner.

\section{Hasil dan pembahasan}

Hasil analisis regresi linier berganda dengan mengggunakan bantuan program aplikasi komputer Statistical Package for Social Science (SPSS) 19 for Windows, maka diperoleh hasil penelitian pengaruh masing-masing variabel citra perusahaan dan kepuasan pelanggan terhadap loyalitas pelanggan dapat digambarkan pada Gambar 1 berikut. 


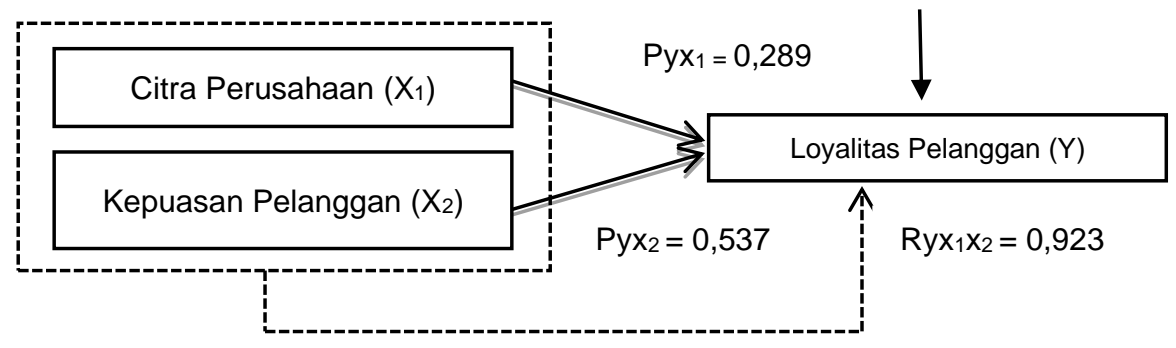

Gambar 1. Struktur Hubungan Citra Perusahaan $\left(X_{1}\right)$ dan Kepuasan Pelanggan $\left(X_{2}\right)$ Terhadap Loyalitas Pelanggan $(\mathrm{Y})$ Tabel 2.

Hasil analisis uji regresi linear berganda yang berupa ringkasan output SPSS dapat dilihat pada

Tabel 2. Hasil Uji Statistik Analisis Regresi Linier Berganda

\begin{tabular}{lcccc}
\hline Variabel Bebas & Koefisien & Sig & $\begin{array}{c}\text { Koefsien } \\
\text { Korelasi }\end{array}$ & $\mathrm{R}^{2}$ \\
Citra Perusahaan & 0,285 & 0,004 & 0,289 & 0,084 \\
Kepuasan Pelanggan & 0,770 & 0,000 & 0,537 & 0,288 \\
Konstanta & $-5,648$ & & & \\
Sig.F & 0,000 & & \\
$\mathrm{R}$ & 0,923 & & \\
$\mathrm{R}^{2}$ & 0,852 & & \\
\hline \multicolumn{2}{c}{ Sumber: Hasil output SPSS 20.0 For Windows Analisis Regresi Linier Berganda }
\end{tabular}

Hipotesis penelitian pertama "Ada pengaruh dari citra perusahaan terhadap loyalitas pelanggan" Berdasarkan rekapan hasil uji regresi berganda pada menunjukan hasil $\mathrm{Pyx}_{1}=0,289$ dengan p-value 0,004 $<\alpha(0,05)$, nilai signifikansi ini lebih kecil dari pada probabilitas 0,05 , maka menolak $\mathrm{H}_{0}$. Hal ini dapat berarti citra perusahaan $\left(\mathrm{X}_{1}\right)$ memiliki kontribusi terhadap loyalitas pelanggan (Y). Nilai t positif menunjukkan bahwa variabel citra perusahaan $\left(\mathrm{X}_{1}\right)$ mempunyai hubungan yang searah dengan loyalitas pelanggan $(\mathrm{Y})$ dengan sumbangan pengaruh sebesar $8,4 \%$, sehingga hipotesis pertama dalam penelitian ini diterima. Hasil penelitian ini menunjukkan ada pengaruh positif dan signifikan citra perusahaan terhadap loyalitas pelanggan. Hasil penelitian ini konsisten dengan penelitian yang dilakukan oleh (Purba, 2017) di mana Citra Perusahaan bepengaruh positif dan signifikan terhadap loyalitas pelanggan. Hal ini juga didukung oleh penelitian oleh (Rahayu et al., 2016)yang memperoleh hasil bahwa citra toko dan nilai yang dipersepsikan memiliki pengaruh signifikan terhadap loyalitas pelanggan. Penelitian (Suratno et al., 2016), juga memperoleh hasil yang menyatakan bahwa citra perusahaan berpengaruh positif signifikan terhadap loyalitas pelanggan. Akan tetapi, (Lai \& et al., 2009) menemukan bahwa loyalitas pelanggan tidak dipengaruhi oleh citra perusahaan.penelitian yang dilakukan (Kurniawati et al., 2014) memperoleh hasil bahwa citra merk tidak berpengaruh signifikan terhadap loyalitas pelanggan.

Hipotesis penelitian kedua "Ada pengaruh dari kepuasan pelanggan terhadap loyalitas pelanggan". Berdasarkan rekapan hasil uji regresi berganda pada menunjukan hasil Pyx $2=0,537$ dengan $\mathrm{p}$-value $0,000<\alpha(0,05)$, yang menyatakan bahwa menolak Ho yang berarti ada pengaruh positif dan signifikan dari kepuasan pelanggan (X2) terhadap loyalitas pelanggan (Y), dengan sumbangan pengaruh sebesar $28,8 \%$, sehingga hipotesis kedua penelitian ini diterima. Dalam penelitian yang dilakukan oleh (Mardikawati \& Naili, 2013) mengenai pengaruh nilai pelanggan dan kualitas layanan terhadap loyalitas pelanggan melalui kepuasan pelanggan pada pelanggan bus efisiensi (Studi PO Efisiensi Jurusan Yogyakarta-Cilacap) hasil penelitiannya menyatakan bahwa kualitas pelayanan berpengaruh positif terhadap loyalitas pelanggan. Hasil penelitian (Suratno et al., 2016) juga memperoleh hasil bahwa kepuasan pelanggan berpengaruh positif signifikan terhadap loyalitas pelanggan. Hasil penelitian (Jean, 2018) memperoleh hasil berbeda dengan penelitian sebelumnya yang meperoleh hasil bahwa kepuasan pelanggan tidak berpengaruh signifikan terhadap loyalitas pelanggan.Hal ini juga didukung oleh penelitian (Rain \& Dkk., 2018) yang memperoleh hasil kepuasan pelanggan tidak berpengaruh signifikan terhadap loyalitas pelanggan karena banyak factor pelanggan menjadi loyal terhadap toko atau perusahaan tertentu.

Hipotesis penelitian ketiga "Ada pengaruh simultan dari citra perusahaan dan kepuasan pelanggan terhadap loyalitas pelanggan". Berdasarkan rekapan hasil uji regresi berganda menunjukan hasil Ryx1x2 
$=0,923$ dengan $p$-value $0,000<\alpha(0,05)$, yang menyatakan bahwa menolak Ho yang berarti ada pengaruh signifikan dari citra perusahaan (X1) dan kepuasan pelanggan (X2) terhadap loyalitas pelanggan (Y), dilihat dari sumbangan pengaruh sebesar $85,2 \%$. Hasil tersebut menunjukan bahwa sebesar $85,2 \%$ loyalitas pelanggan $(\mathrm{Y})$ dipengaruhi oleh citra perusahaan (X1) dan kepuasan pelanggan (X2). Sedangkan pengaruh variabel lain di luar citra perusahaan (X1) dan kepuasan pelanggan (X2) adalah sebesar 14,8 \%. Hal ini dapat disimpukan bahwa variabel citra perusahaan (X1) dan kepuasan pelanggan (X2) secara bersama-sama signifikan berperan dalam meningkatkan loyalitas pelanggan $(\mathrm{Y})$. Sehingga hipotesis ketiga penelitian ini diterima.

(Suratno et al., 2016) menyebutkan bahwa faktor-faktor yang berpengaruh terhadap suatu produk atau jasa adalah sebagai berikut: 1) Nilai (harga dan kualitas). 2) Citra (baik dari kepribadian yang dimilikinya dan reputasi dari merek tersebut), citra dari perusahaan dan merek diawali dengan kesadaran. Produk yang memiliki citra yang baik akan dapat menimbulkan loyalitas konsumen pada merek. 3) Kenyamanan dan kemudahan untuk mendapatkan produk tersebut. 4) Kepuasan yang dirasakan oleh konsumen. 5) Pelayanan, dengan kualitas pelayanan yang baik 6) Garansi dan jaminan. Hasil penelitian Siregar (2019) menunjukkan bahwa kualitas produk, brand image (citra perusahaan) dan kepuasan konsumen berpengaruh positif signifikan terhadap loyalitas pelanggan.

\section{Simpulan dan saran \\ a. Simpulan}

Berdasarkan hasil analisis dari pembahasan yang telah diuraikan pada bab sebelumnya, maka dapat diambil kesimpulan sebagai berikut : 1) Citra perusahaan berpengaruh positif dan signifikan terhadap loyalitas pelanggan Toko Bunga Pertiwi, Cabang Sulanyah, Kecamatan Seririt sumbangan pengaruhnya sebesar 8,4\%. 2) Kepuasan pelanggan berpengaruh positif dan signifikan terhadap loyalitas pelanggan Toko Bunga Pertiwi, Cabang Sulanyah, Kecamatan Seririt, sumbangan pengaruhnya sebesar 28,8\%.3) Citra perusahaan dan kepuasan pelanggan berpengaruh signifikan terhadap loyalitas pelanggan Toko Bunga Pertiwi, Cabang Sulanyah, Kecamatan Seririt, sumbangan pengaruhnya sebesar 85,2\%.

\section{b. Saran}

Adapun saran yang dapat peneliti berikan terkait dengan loyalitas pelanggan adalah sebagai berikut: 1) Bagi Peneliti Selanjutnya, untuk mengetahui dan menganalisis faktor-faktor yang dapat empengarui loyalitas pelanggan, disarankan untuk peneliti selanjutnya, sebaiknya tidak menggunakan satu jenis analisis. Pemakaian beberapa model analisis dapat digunakan sebagai bahan perbandingan agar analisis yang dilakukan dengan akurat karena setiap model analisis memiliki kelemahan dan kelebihan. 2) Bagi Perusahaan, hasil analisis pengaruh citra perusahaan dan kepuasan pelanggan menunjukkan bahwa pada keduanya memiliki pengaruh yang signifikan sehingga diharapkan Toko Bunga Pertiwi, Cabang Sulanyah, Kecamatan Seririt senantiasa memperhatikan dan meningkatkan citra perusahaan serta meningkatkan kepuasan pelanggan dengan memberikan pelayanan maupun menjual produk-produk yang berkualitas dengan harga yang terjangkau sehingga konsumen merasa puas dan menjadi loyal terhadap Toko Bunga Pertiwi, Cabang Sulanyah, Kecamatan Seririt.

\section{Daftar Rujukan}

Ferdinand, A. (2006). Structural Equation Model dalam Penelitian Manajemen. UNDIP.

Jean, H.-W. (2018). The Measurement of World0of-Mouth Communication and an Investigation of Service Quality and Costumer Communication as Potential Antecedents. Journal of Service Research, 4(1), 60-70.

Kurniawati, D., Suharyono, \& Kusumawati, A. (2014). Pengaruh Citra Merek dan Kualitas Produk terhadap Kepuasan dan Loyalitas Pelanggan (Studi pada Pelanggan KFC Cabang Kawi Malang). Jurnal Administrasi Bisnis, 14(2), 581-590.

Lai, F., \& et al. (2009). How Quality, Value, Image, and Satisfaction Create Loyalty at a Chinese Telecom. Journal of Business Research, 6(2), 980-986.

Mardikawati, W., \& Naili, F. (2013). Pengaruh Nilai Pelanggan dan Kualitas Pelayanan terhadap Loyalitas Pelanggan, melalui Kepuasan Pelanggan pada Pelanggan Bus Efisiensi (Studi PO Efisiensi Jurusan Yogyakarta Cilacap). Jurnal Administrasi Bisnis, 2(1), 64-75.

Nguyen, N., \& Leblanc, G. (2016). Corporate Image and Corporate Reputation in Costumers' Retention Decision in Services. Jurnal Retail Dan Jasa, 9, 227-236.

Purba, R. P. (2017). Pengaruh Citra Perusahaan terhadap Loyalitas Pelanggan (Studi Kasus PT. Bintang Utara Perwakilan Dolok Sanggul). JOM FISIP, 4(1), 23-30.

Rahayu, M., Hussein, A., \& Aryanti, R. (2016). Analisis Pengaruh Citra Toko, Citra Merek Produk Private Label, dan Nilai yang Persepsikan terhadap Loyalitas Pelanggan (Studi pada Pelanggan Giant di Kota 
Malang). Jurnal Ekonomi Bisnis, 21(1), 33-45.

Rain, \& Dkk. (2018). Pengaruh Kepuasan Pelanggan terhadap Loyalitas Pelanggan di Toko Kelontong. Jurnal Ekonomi Bisnis, 21(1), 33-45.

Sugiyono. (2011). Metode Penelitian Kuantitatif, Kualitatif, dan R\&D. Afabeta.

Supriyanto, \& Ernawati. (2010). Pemasaran Industri Jasa Kesehatan. Andi.

Suratno, Fathoni, A., \& Haryono, A. T. (2016). Pengaruh Citra Perusahaan dan Kualitas Pelayanan terhadap Loyalitas Pelanggan dengan Kepuasan Pelanggan sebagai Variabel Intervening pada PT Pelabuhan Indonesia III Semarang. Jurnal of Management, 2(2), 1-16.

Wu, P. C. S. (2011). The Effect of Store Image and Service Quality on Brand Image and Purchase Intention for Private Label Brands. Australian Marketing Journal, 19(3), 30-39. 